University of Montana

ScholarWorks at University of Montana

2-1984

\title{
Factors Affecting Nest Site Location in Gila Woodpeckers
}

Jerome J. Korol

Richard L. Hutto

University of Montana - Missoula, hutto@mso.umt.edu

Follow this and additional works at: https://scholarworks.umt.edu/biosci_pubs

Part of the Biology Commons

Let us know how access to this document benefits you.

\section{Recommended Citation}

Korol, Jerome J. and Hutto, Richard L., "Factors Affecting Nest Site Location in Gila Woodpeckers" (1984). Biological Sciences Faculty Publications. 270.

https://scholarworks.umt.edu/biosci_pubs/270

This Article is brought to you for free and open access by the Biological Sciences at ScholarWorks at University of Montana. It has been accepted for inclusion in Biological Sciences Faculty Publications by an authorized administrator of ScholarWorks at University of Montana. For more information, please contact scholarworks@mso.umt.edu. 


\title{
FACTORS AFFECTING NEST SITE LOCATION IN GILA WOODPECKERS
}

\author{
JEROME J. KOROL \\ AND \\ RICHARD L. HUTTO
}

\begin{abstract}
We investigated the locations of Gila Woodpecker (Melanerpes uropygialis) nest sites in Organ Pipe Cactus National Monument, Arizona. A significantly greater proportion of saguaro cacti in arroyos had woodpecker holes than did those on hillsides, ridgetops or desert flats. Saguaros used for nest-hole excavation were taller and more likely to have branches than randomly chosen saguaros. Both active and inactive nest holes were nonrandomly oriented, with the mean vectors of orientation being in northwesterly directions. Variation in nest-hole orientation probably is not due to seasonal differences in excavations because the orientation of spring active (late March) nest holes was not significantly different from that of inactive holes. Some variation in nest-hole orientation is attributable to the structure of the saguaros.
\end{abstract}

Desert birds are often thought to be affected primarily by thermoregulatory constraints in placing their nests (Ricklefs and Hainsworth 1969, Austin 1974). Recently, Inouye et al. (1981) considered the nonrandom orientation of Gila Woodpecker (Melanerpes uropygialis) nest holes in saguaro cacti (Cereus giganteus) to represent such an adaptation. In addition, they suggested that variability about the mean nest-hole orientation might reflect a thermal need for woodpeckers to use holes that are oriented differently at different times of the year or season.

Old woodpecker excavations constitute a volume of valuable historical information that is unique and rarely available to animal ecologists. In this paper we use such information to test the hypotheses that Gila Woodpeckers use a random subset of saguaros for nesting (or roosting) purposes, and that the position and orientation of holes within those saguaros are random. Only the orientation of nest holes has received attention before this study (Inouye et al. 1981). We then compare the mean orientation of inactive holes with that of holes which were being actively used during early spring, to test the hypothesis that the mean orientation of active holes shifts seasonally. Finally, we re-evaluate the possibility that thermal constraints alone can adequately account for the nest site locations of this woodpecker species.

\section{STUDY AREA AND METHODS}

We collected nest site information in Organ Pipe Cactus National Monument, Arizona $\left(31^{\circ} 57^{\prime} \mathrm{N}, 112^{\circ} 48^{\prime} \mathrm{W}\right)$ from $19-29$ March 1981. Vegetation was typical of Sonoran Desert re- gions that receive summer and winter rains (Shreve and Wiggins 1964). A Larrea tridentata-Ambrosia deltoidea association dominated the flats; columnar cacti such as Cereus thurberi, Ferocactus covillei, and Opuntia bigloveii predominated on the steep rocky slopes; and Cercidium microphyllum, Acacia constricta and Olneya tesota dominated the dry creek beds (arroyos). Saguaros were present in each of these physiographic areas.

We assumed that Gila Woodpeckers had excavated most of the holes in the saguaros within our study area. This assumption follows from three observations: 1) in this part of the monument, the Northern Flicker (Colaptes aura$t u s)$ is also known to excavate holes in saguaros, but the holes of the two species can be distinguished by size (Gilman 1915) and the larger flicker holes were rare; 2) data from five $1-\mathrm{km}$ line transects conducted in this location in March-April 1978 (unpubl. data) showed flickers to be six times rarer than Gila Woodpeckers; and 3) only one of 20 active woodpecker nests that we found during our study belonged to a Northern Flicker. We also realize that holes may be excavated for roosting as well as for nesting, but for simplicity and conformity with previously published work we refer to all holes as "nest holes."

In order to characterize woodpecker nest sites, we conducted transects in five different physiographic areas: east-facing slopes, westfacing slopes, ridges, flats, and arroyos. All transects were $40 \mathrm{~m}$ wide and the length and number of transects in each area equalled the distance needed to sample 100 saguaros. Each of the west- and east-facing transects began at the base of a slope and ended no closer than 
TABLE 1. Location of Gila Woodpecker nest holes relative to physiographic area.

\begin{tabular}{lcccccc}
\hline & \multicolumn{5}{c}{ Location } \\
\cline { 2 - 7 } & $\begin{array}{c}\text { East- } \\
\text { facing } \\
\text { slope }\end{array}$ & $\begin{array}{c}\text { West- } \\
\text { facing } \\
\text { slope }\end{array}$ & Ridgetop & Flats & Arroyo \\
\hline $\begin{array}{c}\text { No. saguaros } \\
\text { with holes }\end{array}$ & 3 & 4 & 6 & 6 & 30 \\
$\begin{array}{c}\text { No. saguaros } \\
\text { without holes }\end{array}$ & 97 & 96 & 94 & 94 & 70 \\
\hline
\end{tabular}

$30 \mathrm{~m}$ from a ridge. Ridge transects followed the ridges, and arroyo transects followed arroyo beds and included saguaros within $20 \mathrm{~m}$ of the nearest edge. On the flats, transects were run basically north to south and were discontinued within $30 \mathrm{~m}$ of an arroyo. A rangefinder was used to determine transect widths.

To measure variables that might be important in determining nest hole location and orientation, we recorded the following information for each cactus encountered: height of cactus; number, orientation, and height of branches; number, orientation, and height of holes; and direction to nearest arroyo. Nest hole orientation and direction to nearest point in an arroyo were measured by compass to the nearest $5^{\circ}$. Data were recorded in the same manner for 20 saguaros outside the transect area that contained active Gila Woodpecker nests (holes at which woodpeckers were seen entering and leaving periodically). No data were recorded for saguaros less than $4 \mathrm{~m}$ tall.

The statistical significance of nest-hole and branch orientation was determined through methods described by Batschelet (1965). This technique allows one to test whether the orientation of points is nonrandom, and provides a relative index $(r)$ that reflects the tightness of dispersion around a mean vector of orientation, with a value of 0.0 indicating a high degree of dispersion and 1.0 indicating that all points are oriented in the same direction.

\section{RESULTS}

\section{SAGUARO SELECTION}

The presence of woodpecker nest holes was dependent upon physiographic area (Table 1). Significantly more saguaros in arroyos had woodpecker holes than did those in any of the other areas $(G=47.1, P<.001)$. The proportion of saguaros with holes did not differ significantly among the four non-arroyo areas $(G=1.55, P>.05)$. The dependence between presence of holes and physiographic area persists when the effects of saguaro height and presence of branches are kept constant ( $G=$ $33.1, P<.01)$.

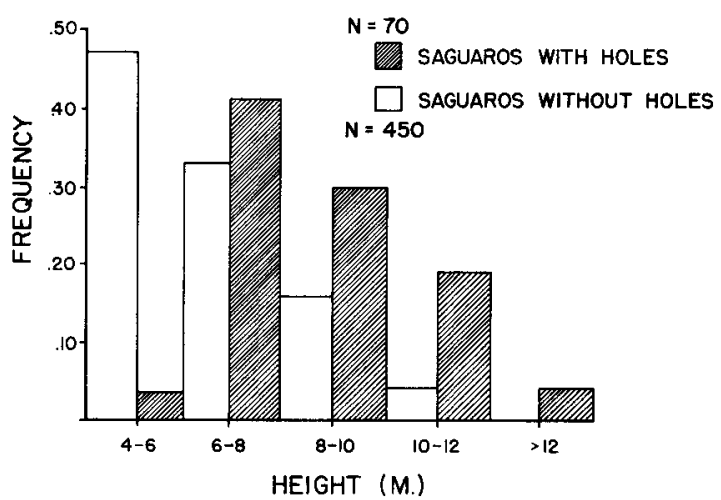

FIGURE 1. Frequency histograms representing the height distribution of saguaros that did or did not contain Gila Woodpecker holes.

The saguaros that were used for nesting purposes were significantly taller than would be expected if the woodpeckers were using them in proportion to their availability; we found no saguaro shorter than about $4 \mathrm{~m}$ with a woodpecker nest hole, and even restricting analysis to saguaros that were greater than or equal to $4 \mathrm{~m}$ in height, the taller saguaros were used disproportionately more often than the shorter saguaros $(G=82.3, P<.001$; Fig. 1$)$. The mean height of saguaros with holes was significantly $(t=9.4, P<.01)$ greater than those without holes (8.6 vs. $6.4 \mathrm{~m}$, respectively). Inouye et al. (1981) reported the mean height of saguaros with nest holes to be $9.6 \mathrm{~m}$.

Among saguaros that were used, the number of holes present in a given saguaro was significantly positively correlated $(r=.33, P<.001)$ with saguaro height and increased with saguaro height at a rate that was slightly less than expected based on either saguaro surface area or volume (Fig. 2). Thus, we detected no preference for a particular height class since no height class contained saguaros that had disproportionately more or fewer holes than predicted from the regression line.

Of saguaros taller than $4 \mathrm{~m}$, the presence of nest holes was significantly $(G=63.9, P<$ $.001)$ positively associated with the presence of branches (Table 2). This association also held true when the five physiographic areas were considered separately. The conditional

TABLE 2. The distribution of saguaro use relative to the presence or absence of branches.

\begin{tabular}{lcc}
\hline & \multicolumn{2}{c}{ Nest holes } \\
\cline { 2 - 3 } & Present & Absent \\
\hline Branches present & 46 & 81 \\
Branches absent & 24 & 369 \\
\hline
\end{tabular}




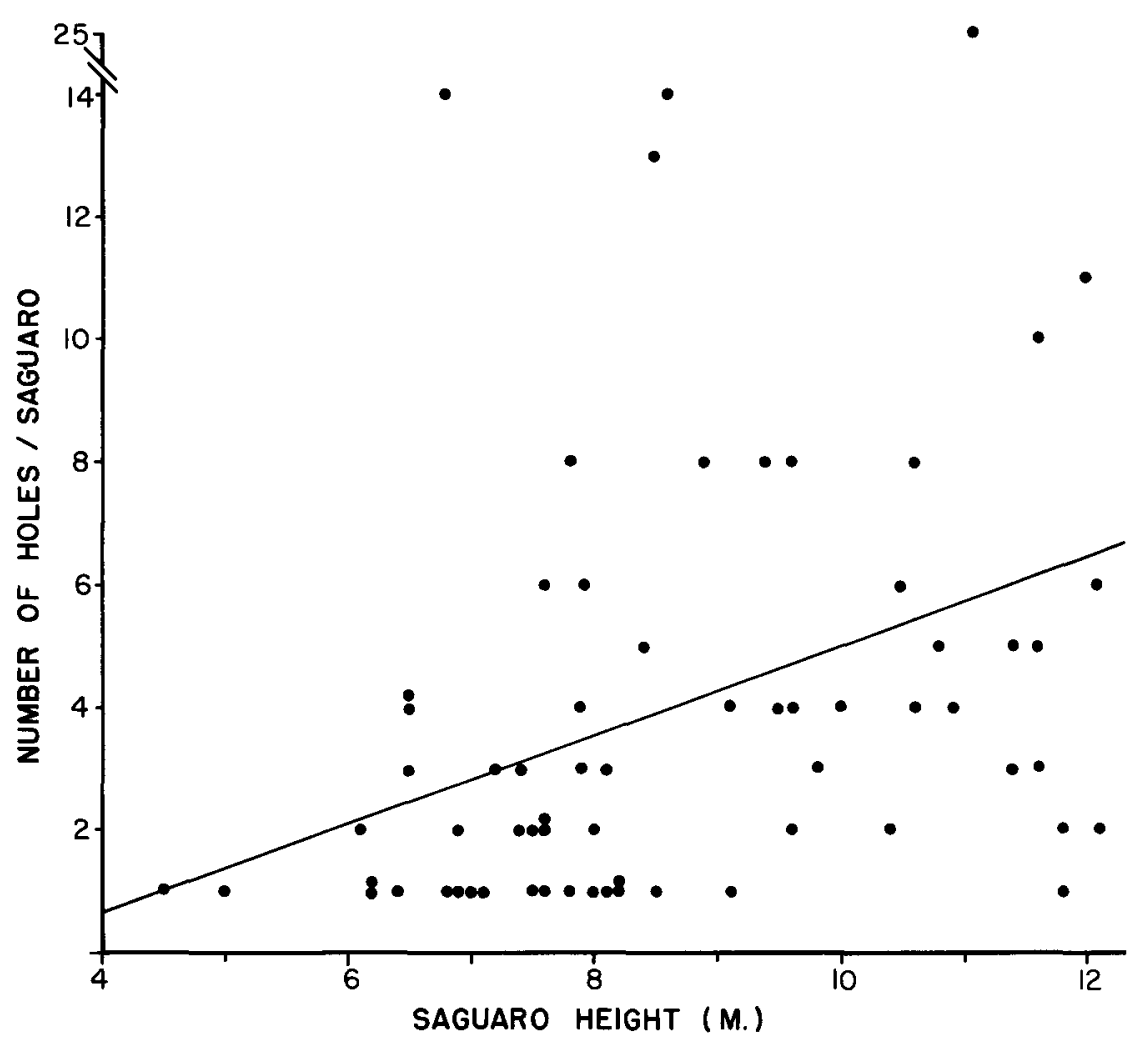

FIGURE 2. The number of Gila Woodpecker holes present in a saguaro in relation to saguaro height. No height range contains saguaros with disproportionately more holes than expected from the regression.

probability that a cactus would have branches if it contained one or more nest holes was $66 \%$, while the probability that a nest hole would be present given the saguaros had branches was much less $(36 \%)$.

We tested the hole, height, and branch variables for conditional independence using a 3-way analysis of association (Sokal and Rohlf 1981: 750) and found that the presence of holes depended upon height, given the presence or absence of branches $(G=37.8, P<$ $.001)$. Furthermore, the presence of holes depended upon the presence of branches, given the height of the saguaro $(G=19.4, P<$ $.001)$.

\section{NEST SITE CHARACTERISTICS WITHIN SAGUAROS}

We determined the nest site characteristics of 20 active and 171 inactive woodpecker nest holes throughout the five physiographic areas. The relative height of nest holes within saguaros was inversely related to saguaro height such that there existed a maximum absolute height of about $7 \mathrm{~m}$, beyond which woodpecker excavations were rarely found (Fig. 3).

The active nest holes were significantly nonuniformly oriented around the saguaros (Fig. 4 ), with the mean vector of orientation equal- ling $38^{\circ}$ north of west $(z=5.26, r=.49, P<$ $.01)$. The inactive nests were also significantly nonuniformly oriented (Fig. 4), with the mean vector of orientation equalling $17^{\circ}$ north of west $(z=7.75, r=.21, P<.01)$. Moreover, inactive nests were not significantly differently oriented from the active nests $(z=5.26, P<$ $.01)$. Although the distribution of active and inactive nests was significantly nonuniform, it

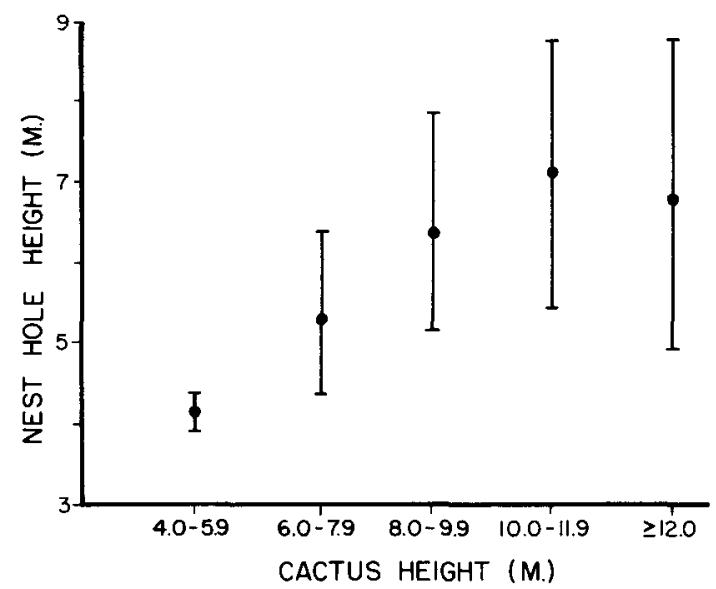

FIGURE 3. The mean absolute height ( \pm 1 standard deviation) of Gila Woodpecker nest holes in relation to saguaro cactus height. 


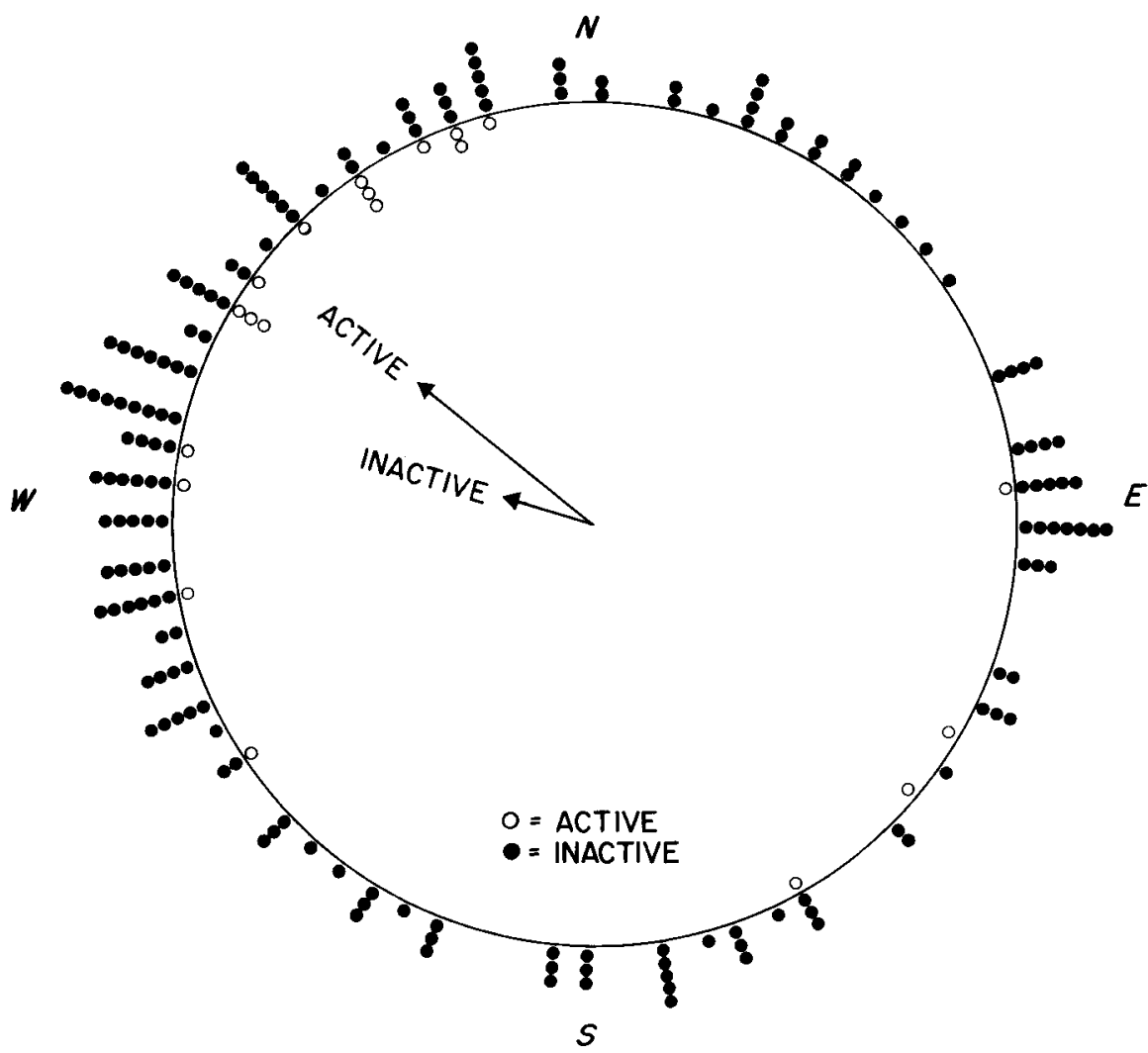

FIGURE 4. The compass orientation of active and inactive Gila Woodpecker nest-hole entrances. Arrows indicate mean directions of orientation and arrow lengths are inversely proportional to the amount of dispersion about the mean $(r)$.

is important that considerable dispersion existed (indicated by the relatively low $r$ values) and that the nonrandom orientation was largely a statistical phenomenon; many holes were oriented in directions other than northwest.

Over one-fourth of the saguaros with nest holes also bore one or more "adjacent branches"-branches whose base was lower and tip higher than the height of the nest hole. The orientation of 17 active and inactive nest holes relative to the direction of pairs of adjacent branches was nonrandom $(z=16.2, r=.98$, $P<.01$ ); nest holes tended to bisect the acute angle formed by the directions of orientation of the two branches (Fig. 5). These 17 nest holes were themselves randomly oriented with respect to compass direction $(z=0.12, r=.08$, $P>.05$ ).

Nest holes were randomly oriented with respect to the direction to the closest arroyo $(z=$ $0.20, r=.11, P>.05$ ).

\section{DISCUSSION}

The disproportionately high use of saguaros in arroyos is not necessarily because the thermal environment is most favorable there. An

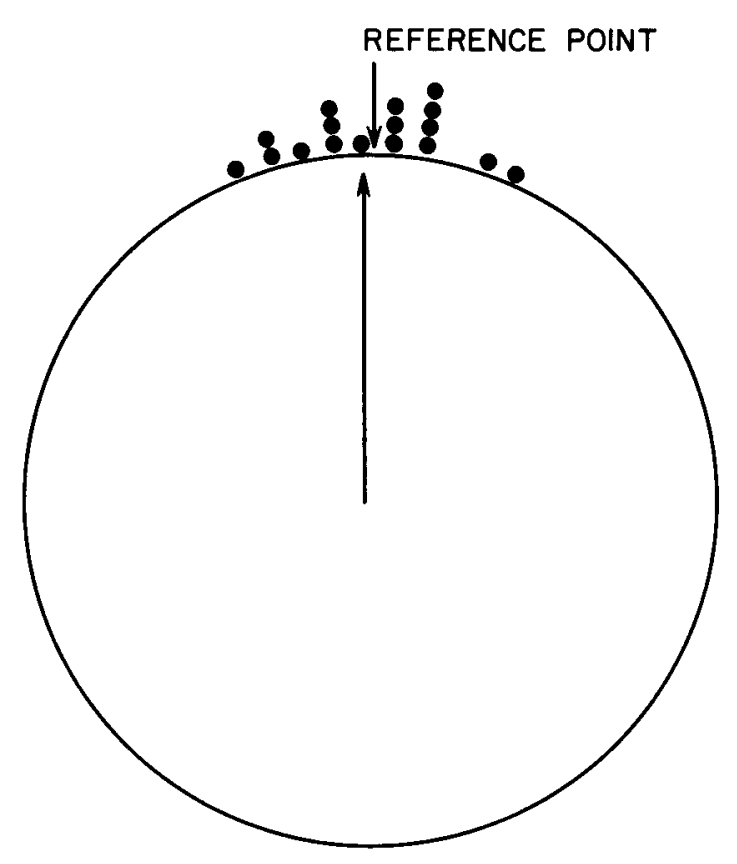

FIGURE 5. The orientation of Gila Woodpecker nest holes near a pair of branches. Reference point is the direction that bisects the acute angle formed by orientation of the two branches. 
equally plausible alternative is that the woodpeckers forage primarily in the arroyos. The latter interpretation would be consistent with Bent's (1939) statement that the Gila Woodpecker feeds on food items that are either restricted to, or much more common in, the wash environment, such as insects in dead wood, fruits, berries, and bird eggs.

The reasons why taller saguaros are used disproportionately more often than shorter ones are not entirely clear, but we suspect that there are problems associated with smaller saguaros that may not exist with larger ones. For example, excavating in a small structure may be difficult, predation rates may increase closer to the ground, or thermal stress may become a significant factor closer to the ground. Although the taller saguaros are used most often, there also appears to be an upper limit (Fig. 3) to the height of nest excavations. Since structural change in saguaros is more likely to be associated with relative, rather than absolute, height, the upper limit to hole height may be set by the energetic constraints of travel, just as the upper limit in vertical flight of Northwestern Crows (Corvus caurinus) is likewise constrained (Zach 1979).

The association between the presence of branches in the saguaros is apparently due to the woodpeckers' preference for saguaros with branches. This follows from our finding that we were more likely to see branches, if a saguaro had nest holes than we were to see a nest hole, if a saguaro had branches. The alternative explanation for the association would be that the saguaros tend to branch in response to the presence of nest holes. The latter interpretation would also be inconsistent with the findings of Yeaton et al. (1980), who concluded that branching in saguaros is related to moisture availability.

The orientation of woodpecker nest holes has received considerable attention (see McClelland [1977] for a brief review). Nest hole orientations differ considerably among species and vary geographically within a species. The Gila Woodpecker appears to be unique, however, because it tends to excavate nest holes in a northwesterly direction. One factor that has been important in accounting for nest hole orientation in a variety of woodpecker species has been the tendency for woodpeckers to excavate on the downward side of leaning trunks and branches (Conner 1975). We found so few nest holes in nonvertical portions of saguaros that this factor must be unimportant in determining the direction of nest hole orientation in Gila Woodpeckers.

The nonrandom orientation of nest holes is generally attributed to thermal constraints (In- ouye et al. 1981), suggesting that variability in nest hole orientation might be accounted for by seasonal differences in the orientation of newly excavated nest holes. Indeed, the orientation of nest entrances of Cactus Wrens (Campylorhynchus brunneicapillus; Ricklefs and Hainsworth 1969, Austin 1974) and House Sparrows (Passer domesticus; McGillivray 1981) has been shown to differ significantly with time of season. Inouye et al. (1981) concluded that the variation in nest hole orientation of Gila Woodpeckers may also result from seasonal differences in the optimal orientation of nest and/or roost holes. If this were true, we would expect the orientation of early (mid-March) nests to be clustered fairly tightly around a given direction, and we would also expect that the direction would differ significantly from the mean direction of orientation recorded for the entire group of inactive holes. This was not the case. The 20 active holes were scattered considerably in their orientation $(r=$ .49 ) and the mean direction of orientation did not differ significantly from the mean direction of all inactive nests. The variability in nest hole orientation can apparently not be explained on the basis of seasonal shifts in the mean orientation of nest holes that are used.

One important variable contributing to the orientation of about $10 \%$ of the nest holes in this study was the positioning of branches relative to nest holes; holes were always excavated within the acute angle formed by adjacent branches when they were present.

In conclusion, the nest sites used by Gila Woodpeckers appear to be determined by several factors. Foraging constraints probably dictate which saguaros are used, while foraging, predatory, thermoregulatory, and architectural constraints probably all limit the height and orientation of nest holes. We feel it unlikely that any single factor can adequately account for the variability in location of Gila Woodpecker nest sites.

\section{ACKNOWLEDGMENTS}

We thank the personnel of Organ Pipe Cactus National Monument for permission to conduct the study there and for their many forms of assistance. We also thank the Zoology Department of the University of Montana for financial support associated with the 1981 Field Ecology course, and Joe McAuliffe for comments on a draft of the manuscript.

\section{LITERATURE CITED}

Austin, G. T. 1974. Nesting success of the Cactus Wren in relation to nest orientation. Condor 71:216-217.

BAtSCHELET, E. 1965. Statistical methods for the analysis of problems in animal orientation and certain biological rhythms. American Institute of Biological Sciences, Washington, DC. 
Bent, A. C. 1939. Life histories of North American woodpeckers. U.S. Natl. Mus. Bull. 174.

ConNer, R. N. 1975. Orientation of entrances to woodpecker nest cavities. Auk 92:371-374.

Gilman, M. F. 1915. Woodpeckers of the Arizona lowlands. Condor 17:151-163.

INOUYE, R. S., N. J. Huntly, AND D. W. INOUYE. 1981. Nonrandom orientation of Gila Woodpecker nest entrances in saguaro cacti. Condor 83:88-89.

MCClelland, B. R. 1977. Relationships between holenesting birds, forest snags, and decay in western larchDouglas-fir forests of the northern Rocky Mountains. Ph.D. diss., Univ. of Montana, Missoula.

McGillivray, W. B. 1981. Climatic influences on productivity in the House Sparrow. Wilson Bull. 93:196206.

RickleFs, R. E., AND F. R. HAINSWORTH. 1969. Temperature regulation in nestling Cactus Wrens: the nest environment. Condor 71:32-37.

The Condor 86:78

(c) The Cooper Ornithological Society 1984

\section{RECENT PUBLICATIONS}

Breeding Biology of the Adélie Penguin.-David G. Ainley, Robert E. LeResche, and William J. L. Sladen. 1983. University of California Press, Berkeley. 244 p. $\$ 27.50$. Seabirds are longer-lived than most landbirds, and must therefore be studied for longer periods in order to understand their life history. Here is the outcome of fifteen seasons of fieldwork in the penguin rookeries at Cape Crozier, Ross Island, Antarctica. Individually marked, knownage birds were studied throughout, and many of them were observed during several seasons after being banded. Integrating these findings with those from other studies, the report describes breeding activities in detail and analyzes how age, experience, and other factors influence breeding success. It then examines the size and age structure of the Crozier population, and finally, the variables that regulate it. The book is crammed with data (drawn from impressively large samples), yet it is well written, with chapter summaries and other passages to guide the reader. It makes a major contribution to our knowledge of the Adélie Penguin and sheds light on the life history patterns of other large seabirds. Between the lines, it shows the kinds of biological questions that can explored only by long-sustained investigations. Illustrations, appendices, references, index.
Shreve, F., AND I. L. Wiggins. 1964. Vegetation and flora of the Sonoran Desert. Stanford Univ. Press, Stanford, CA

Sokal, R. R., AND F. J. Rohlf. 1981. Biometry. W. H. Freeman and Co., San Francisco.

Yeaton, R. I., R. Karban, ANd H. B. Wagner. 1980. Morphological growth patterns of Saguaro (Carnegiea gigantea: Cactaceae) on flats and slopes in Organ Pipe Cactus National Monument, Arizona. Southwest. Nat. 25:339-349.

ZACH, R. 1979. Shell dropping: decision making and optimal foraging in Northwestern Crows. Behaviour 63:106-117.

Department of Zoology, University of Montana, Missoula, Montana 59812. Received 22 February 1983. Final acceptance 30 June 1983.

The Arctic Skua/A study of the ecology and evolution of a seabird.-Peter O'Donald. 1983. Cambridge University Press, Cambridge. 324 p. $\$ 49.50$. Arctic Skuas (known to us as Parasitic Jaegers, Stercorarius parasiticus) occur in three main phenotypes that vary in frequency from mostly dark in the southern colonies to almost entirely pale in the north. The ecological and genetic factors maintaining this stable, clinal polymorphism are the chief subject of this book. It is largely based on original, long-term research conducted at the Fair Isle Bird Observatory, between the Shetland and Orkney islands. The stage is set with chapters on the numbers and distribution of birds, their feeding behavior, and breeding biology. The following chapters treat genetics, demography, and sexual selection, incorporating general theory where needed to understand the specific analysis. Despite this material, the argument is at an advanced level and, to be grasped fully, calls for some prior knowledge of population genetics. Several appendices go further into the mathematical and statistical methods for analyzing bird populations and mating patterns. Informative as it is about jaegers, the book will probably be of wider interest to those who are investigating polymorphism, selection, or mating in other birds. Illustrations, references, index. 